\title{
CAPACITY BUILDING FOR RS \& GIS TECHNOLOGY APPLICATIONS: STUDENT REMOTE SENSING AND GEOSPATIAL PROGRAMME IN ACADEMIC INSTITUTIONS
}

\author{
Murthy Remilla $^{1, *}$, J.K. Kishore ${ }^{1}$
}

${ }^{1}$ U R Rao Satellite Centre, Bangalore, Karnataka, (mremilla, jkk)@isac.gov.in

\author{
Commission V: WG V/1
}

KEY WORDS: Remote Sensing, GIS, Capacity Building, National GIS, Student Remote Sensing Programme

\begin{abstract}
:
Digital India program aims to transform India into a knowledge economy with Smart Cities / Smart Villages etc. It depends significantly on Remote Sensing (RS) and Geographic Information Systems (GIS). It requires enormous computing Infrastructure and RS-GIS trained professionals along with Information and Communications Technology (ICT). Satellite based Earth Observation (EO) data volumes are increasing at a rate of several Terabytes a Day in heterogeneous formats (different spatial and temporal resolutions in optical, thermal and microwave). The recent trends towards free and open access policy creates unprecedented opportunities for both industrial and academic research communities for Big Data applications.

During the last decade, Engineering Institutions across the nation have improved significantly in terms of high end computing, Wi-Fi campuses and qualified faculty to help students. Agricultural Universities/Colleges are also making extensive use of RS-GIS technology. Many research papers are also being published by students from Engineering / Agricultural Institutions in the domain of RS-GIS. Here lies the scope for enhanced collaboration between ISRO / Industry and Academia in the form of Student Remote Sensing and Geospatial programme (SRSGP) for scaling up operational services to sustain Digital India and boost the Geospatial Readiness Index of the nation. It will expand the handson experience of the student community and enrich their job-readiness in the industry and lead to development of trained RS-GIS professionals. It has the potential to make Digital India the global destination for RS-GIS applications similar to how Y-2K made India the global IT-destination.
\end{abstract}

\section{Introduction}

The Government of India has launched the Digital India programme with the vision to transform India into a digitally empowered society and knowledge economy. The Digital India initiative includes plans to connect rural areas with high-speed internet networks. Digital India program is to transform India into a digitally empowered society and knowledge economy [1]. To reverse the migrations to cities, the Smart Village concept has been taken up to ensure high quality of living to the people to fulfill the vision of Mahatma Gandhi and Sir Mokshagundam Visveswariah who wanted the people in villages also to have the best of facilities as in urban areas [3].

Spatial information is of paramount importance in such services and RS \&GIS is a vital dimension of Digital India. As remote sensing technology continues to improve in resolution, swath, high data rates, and multiple bands, the data base will enlarge and increase the potential power of applications of a Geographic Information System. The increasing number of missions will provide much larger volumes of data in heterogeneous formats and the recent trends towards free and open access policy creates opportunities for both industrial and academic research communities. Big Data and GEOSpatial technologies are needed for EO applications

The goal of Digital India requires an army of RS-GIS professionals and this requires a distributed approach involving Academic Institutions / Industry and student communities as part of the ECOSYSTEM apart from the existing traditional National - State Remote Sensing Service Centers and Agencies. When thousands of RS-GIS trained staff is needed across the nation for Digital India, it brings memories of Y-2K which taught the importance of SCALING up resources in fast track mode.

The SRSGP @ Academic Institutions offers hope and scope to scale up resources for Digital India in tune with global trends. It will also help in developing Data Scientists / Engineers. A 'geo-intelligent' workforce and higher education institutional capacity is a key determinant of a country's geospatial domain strengths.

In tune with global trends, the United States of America and the United Kingdom are the leading geospatial ready countries in the Countries Geospatial Readiness Index-2018.

Presently, India is in the Top-25 nations in terms of Geospatial Readiness Index. Hence, the Student Remote Sensing and Geospatial Programme is being proposed to boost the capability and capacity for applications and operations so that India will be in Top10 nations of the world in terms of Geospatial Readiness Index in the coming 5 years.

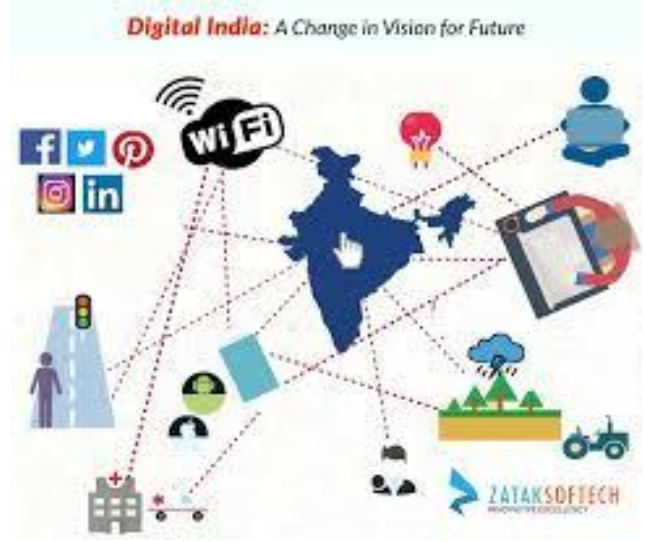

Fig 1 Digital India to boost the nation

Outline of the paper: Section 2 deals with Global trends in RS-GIS: National and Local Context for SRSGP in India. Section 3 gives a brief description of the National and State GIS for Digital India. The importance and the role of Engineering Institutions and Agricultural 
Universities for Digital India is discussed in section 4. In section 5, the relevant computing technology status is presented.

\section{Global trends in RS-GIS}

In its second edition, the Countries Geospatial Readiness Index (CGRI-2018), has made a detailed study of 50 nations to assign the ranking and also highlighted the need to develop an inclusive and collaborative geospatial ecosystem strategy. The Geospatial Readiness Index is a blueprint for stakeholders (decision makers both public and industry) to use to develop efficient geospatial capabilities so as to maintain a global competitive advantage - and to deliver better geo-enabled services to consumers - contributing to robust national growth and development. In perspective, the CGRI2018 establishes USA, UK, Germany, Singapore and the Netherlands as the leading geospatial ready countries.

(Ref:https://www.geospatialworld.net/article/worlds-geospatialready-countries)

The Countries Geospatial Readiness Index (CGRI) is a comparative assessment of 50 countries spread across geographies, at different development stages, evaluated and assessed for their geospatial maturity. The index is an important tool for decision makers to comprehend the areas for developing geospatial capabilities for value-creation, economic growth, and overall national development. The index assesses a country's geospatial capabilities on the following Pillars:

Data Infrastructure

Policy Framework

Institutional Capacity

User Adoption Level

Industry Fabric

In fact, all the leading geospatial ready countries have an enabling national geospatial eco-system. The users of these leading geospatial ready countries are able to derive multifold benefits as they have the capability to integrate geospatial information with applications/hardware and software of different ecosystems such as IT and Engineering. Spatial integration, with the digital ecosystem, leads to the creation of unique solutions generating huge economic and social value for an economy. These leading geospatial ready countries have a vibrant geospatial industry-academia ecosystem.

We have entered an era of big data. Our ability to acquire remote sensing data has been improved to an unprecedented level. The volume of global data archive could be on the Exabyte level. When characterizing big data, it is popular to refer to the $3 \mathrm{Vs}$, i.e., remarkable growths in Volume, Velocity and Variety of data. Big data can also be referred to data from different sources. Remote sensing data often differ in resolutions, revisit cycle, spectrum, and mode of imaging. Therefore, we can choose different remote sensing systems and datasets for different applications. For remote sensing big data, the $3 \mathrm{Vs}$ could be more concretely extended to characteristics of multi-source, multi-scale, high-dimensional, dynamic-state, isomer, and non-linear characteristics. More characteristics could provide us more information. It is both the opportunity and challenge for remote sensing communities.

\subsection{Open Data Policy}

LANDSAT was the pioneer remote sensing programme and has completed over 40 years. The open data policy has enabled educational institutions and students to come up with many applications and the utilization of LANDSAT data has increased substantially. The economic value in terms of the applications rendered has been truly remarkable. Along similar lines, the Copernicus Programme in Europe has a liberal data policy which enables academic institutions and students to develop new applications. In tune with global trends, even ISRO satellite data is available@BHUVAN and can be downloaded by Academic Institutions for developing applications and also for R \& D.

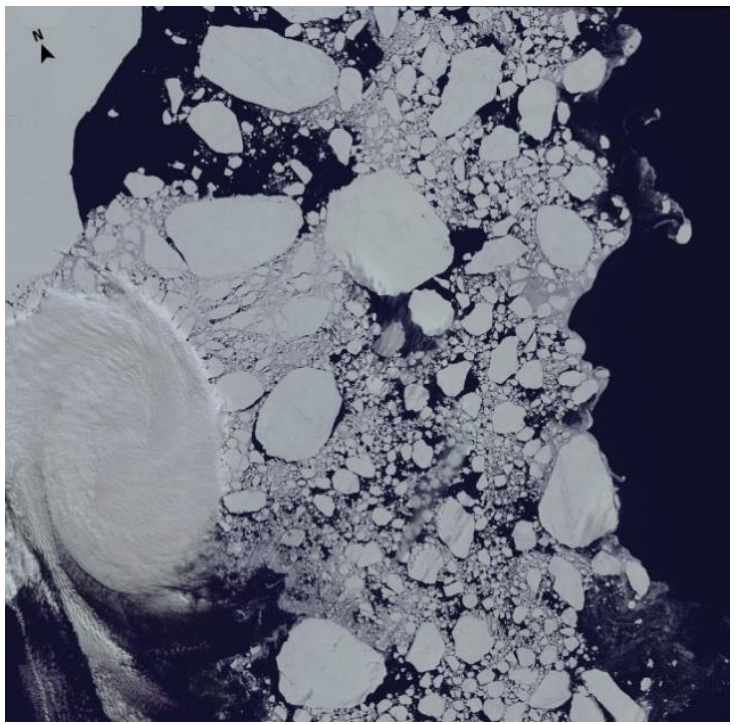

Fig 2 Image of the Ross Archipelago near the McMurdo Station in Antarctica

The above image was acquired on January 1, 2018, by Landsat 8, almost exactly a decade after USGS and NASA officials signed off on a Landsat Data Distribution Policy that made Landsat images free to the public. https://eros.usgs.gov/headlines/free-open-landsatdata-unleashed-power-remote-sensing-decade-ago

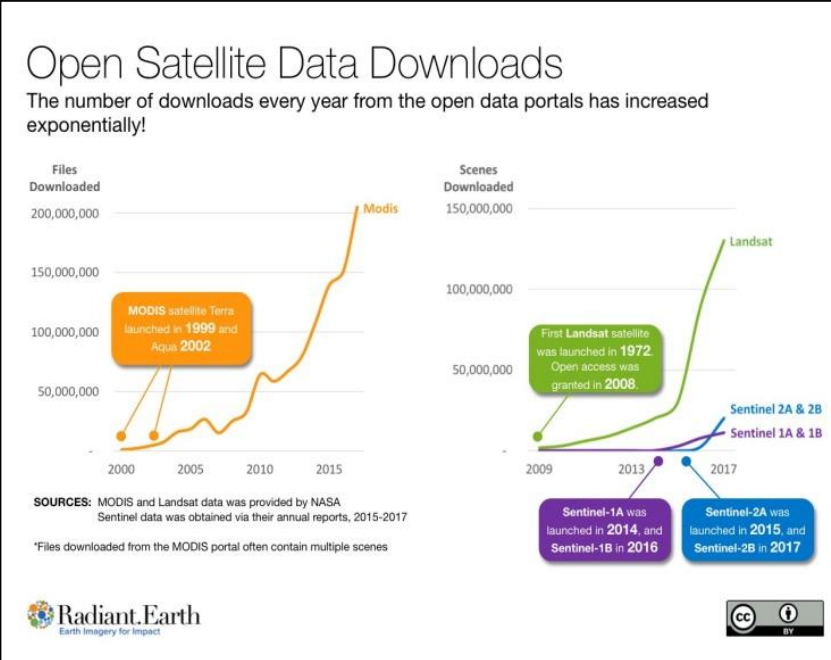

Fig 3 Increase in open satellite data downloads. https://www.geospatialworld.net/blogs/role-of-governmentsatellite-data-in-advancing-global-development/

In recent years, thanks in part to cloud computing, this data has become more readily accessible to a wider audience. To give an idea of the scale, over 15 Petabytes of data from Sentinel 2 has already been downloaded by users worldwide since the satellites launched in 2015 and 2017.

\section{$2.3 \mathrm{RSCC}$}

The goal of the Remote Sensing Core Curriculum (RSCC) is to provide the resources to support a state-of-the-practice educational experience. The RSCC is primarily geared towards university level education [4].The RSCC is composed of submissions from a variety of authors from academia, government, and industry on a volunteer 
basis. The RSCC was developed along the model of the NCGIA GIS Core Curriculum, to "augment the nation's supply of experts in remote sensing technology by providing a set of readily accessible, adaptable teaching materials." The RSCC is intended to provide a knowledgebase of theory and techniques to advance the understanding and use of remote sensing and geospatial science. Between January 1, 2014 and September 24, 2014 the site received 112801 unique visitors from countries in every continent but Antarctica [4].The global efforts show the potential and the scope to broaden the base of RS-GIS applications via Academic Institutions. It is possible to have RS-GIS courses in UG (already happening in many places) and if possible offer even a Diploma Certificate course for RS-GIS to work in projects for Digital India. This can be seen as an intermediate step to PG / Ph.D. courses. This is similar to the Microsoft/ Oracle certified professionals.

\section{National and State Level RS \& GIS Initiatives for Digital India}

ISRO has launched and operationalized several Remote Sensing Satellites under its IRS program to cater to land, ocean and other resources monitoring, environmental studies and decision making. Digital India triggers an initiative in evolving a research agenda for a number of earth resources applications associated with RS and GIS technology that could enhance user specific value addition and optimal information derived for easy, quick reach and utilization to the end user.

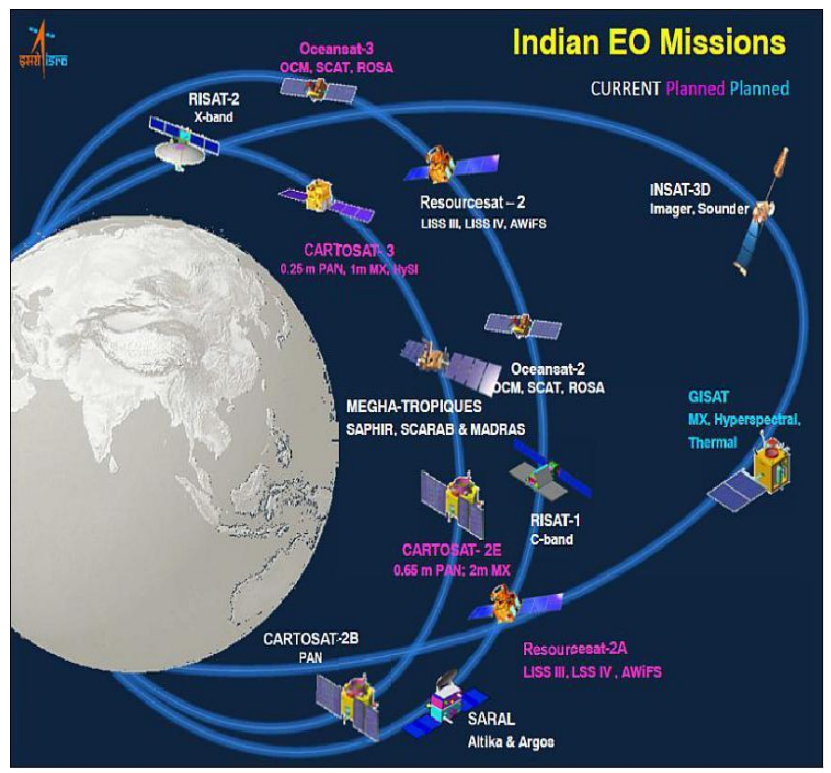

Fig 4 India's Earth Observation Program

Under the aegis of National Remote Sensing Centre (NRSC), five Regional Remote Sensing Centers (RRSCs) viz, South (Bengaluru, Karnataka) , West (Jodhpur Rajasthan), East (Kolkata, West Bengal), North (Dehradun, Uttaranchal), and Central (Nagpur, Maharashtra) are supporting various remote sensing projects specific to their regions as well as at the national level. RRSCs also provide expert advice and consultancy towards promotion of technology in the country.

Today, majority of the government departments and public sector units as well as private and services agencies are the users of RS and GIS. Public and Private sector companies in India employ RS \& GIS professionals which shows the job potential for SRSGP.

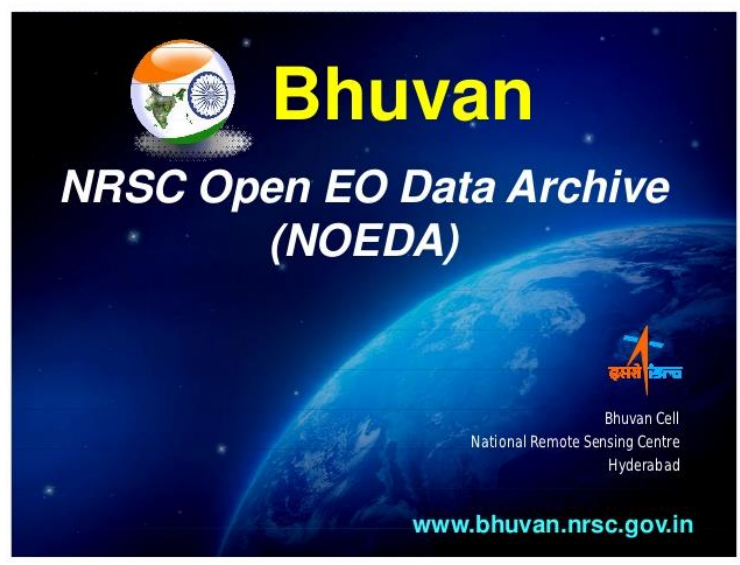

Fig 5. ISRO-NRSC-Bhuvan-Open EO data portal

\section{National GIS}

India is a vast country and in today's rapidly changing world, India recognizes that nations that possess a sound and progressive GIS vision supported by front end RS data centers will be the leader. It calls for a National level GIS with integrated databases and seamless data fusion and on-the-fly delivery. India's vision for a comprehensive National GIS is a project of massive scale and can be made successful only by involving the Government Agencies, corporate sector, educational institutions etc. National Centre of Geo-Informatics will be GIS platform for sharing and collaborating GIS data source, location based analytics and 'decision support system' serving to government departments across the country to ultimately served the public. National GIS of India based on RS data is an innovative program planned within the country's Twelfth Five Year Plan that has generated much interest. The national and state GIS will also boost education and research in GIS with specific school, university, and research programs focused on training the leaders of tomorrow in spatial thinking concepts and the core principles of GIS

\section{Need for Capacity and Capability Building in India in the domain of RS-GIS}

Presently, India is in the Top-25 nations in terms of Geospatial Readiness Index. Hence, the Student Remote Sensing and Geospatial Programme is being proposed to boost the capability and capacity for applications and operations so that India will be in Top10 nations of the world in terms of Geospatial Readiness Index in the coming 5 years

In view of the National requirements and Global trends, there are two dimensions to the upscaling - Infrastructure on one side and Trained Manpower on the other. Such a massive national programme and associated goals requires High Computing Power and High Connectivity along with adequate number of adequately qualified professionals which can be met with the support of Engineering Institutions / Agricultural Universities and Industry.

\section{Engineering Institutions/ Agricultural Universities in Digital India}

Apart from the existing remote sensing agencies, at both national and state level ( NRSC/ RRSCs/ SRACs), the huge potential of the Engineering Institutions/ Agricultural Universities \& colleges and the Student community also needs to be tapped as part of capacity and capability building efforts to deliver the services for National RS-GIS / State RS-GIS / Digital India. Many research papers are being published by students from Engineering Institutions in the domain of RS-GIS in various conferences and journals. The skills required to be a successful GIS professional changed and evolved 
over the years. Though an elective of the civil engineering stream, it can also be taken up by the students of other subjects, especially geography and geology, as a specialization. There are a number of career opportunities in this field, both in India and abroad. Thus, candidates from a wide variety of professional and educational backgrounds (e.g. Geography, Urban Planning, Cartography, Engineering, Computer Science, water resources, disaster Management and so on) aspire to be successful GIS professionals.

TIER - I cities like Bangalore / HYD / Chennai capital regions alone may have more than 50 good Engineering colleges and if we add institutions in Tier-II cities like Mangalore / Mysore / Dharwad / Visakhapatnam / Vijayawada / Tirupati/ Warangal / Madurai / Tanjavur/ Coimbatore / Tiruchi/ Trivandrum / Cochin etc., etc., additional 35 to 40 colleges will be present. Many Engineering Colleges in Bangalore / HYD / Chennai hold IEEE conferences and their faculty / students also publish in these conferences. Even some Engineering Colleges in Tier-II cities are also conducting IEEE and national workshops and publishing good results. As Engineering College institutions have established very good Computing Laboratories they are in a position to establish RS - GIS lab by installing ERDAS / ENVI / GIS Software etc.,. Already, many of them have Image Processing and computer visualization labs in leading Engineering Colleges.

It is also interesting to note that many Agricultural Universities / colleges are also making extensive use of RS-GIS and have established the necessary computing infrastructure. UG/PG students need to be enabled to develop Remote Sensing / GIS / Bhuvan applications and get them evaluated by our Experts before deploying them. The ability to download the data / process it on ERDAS etc., and upload it back for verification and if possible to have guidance via Video conference / Skype etc., Training programs periodically conducted by NRSC by its dedicated training division could be used by the prospective student community either off-site or on-site. ISRO's own Integrated Geographic Information and Image Processing Software (IGiS) jointly developed by industry with Space Applications Centre (SAC) provides a very affordable solution for Image Processing and GIS to the consumers.

Example 1: An example of successfully using the RS, GIS, GPS and IT (Geoinformatics) is at the Visvesvaraya Technological University-Extension Centre (VTU-EC) hosted by the Karnataka State Remote Sensing Applications Centre (KSRSAC) where a full time four semester M.Tech programme is conducted with high facilities for teaching, research and applications of the RS-GIS technology.

Example 2: The RS - GIS lab @ TCE, Madurai is another good success story and Madurai is Tier - II city [ $[\underline{6}]$

Example 3: It is very interesting to see that RS-GIS lab @ VNIT Nagpur uses ERDAS etc., and they have done many interesting RSGIS applications. The digital infrastructure available in the lab is a good benchmark for other Engineering Institutions. Fig 1 shows snapshot of ERDAS [7].

Example 4: The JK Lakshmipat University hosted the National Symposium on Geomatics for Digital India in Dec 2015 along with ISRS-ISG in Jaipur which is a Tier-II city[].

The above success stories show that if the same can be replicated at the Engineering Institutions / Agricultural Universities \& Colleges across the nation especially in Tier-II cities, it will really boost DIGITAL INDIA / Smart Cities / Smart Villages.

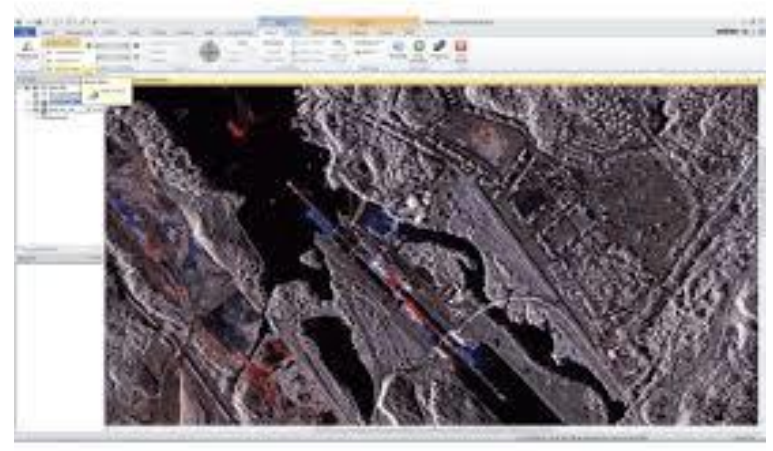

Fig 6. A Snapshot of ERDAS

There must be at least 100+ Engineering Colleges in the Southern Part of India which can REPEAT the success story of TCE, Madurai which is a TIER-II city( Bangalore / Chennai/ HYD are Tier-1 Cities ). If we extend it to rest of India (Western / Central / Northern / North-East, North-west), at least another 300+ Engineering Colleges will be available. If we also include Agricultural Universities / Colleges, we will probably touch 500 Engineering / Agricultural Institutions across the Nation i.e., it will be covering all the districts of the nation. Many of them have also been accredited by NAB / NAAC etc. A huge talent pool is available. Assuming that DATA is made available to them through national data centers, we have a golden chance to spread the RS - GIS across the board which will increase the outreach as more computing power becomes available for processing our RS data and it can be done in collaborative mode based on the experience / expertise of ISRO - NRSC / RRSCs / IIRS etc.

The amount of computing power that is needed along with the trained man-power is going to hold the key to success of Digital India to be successful across the length and breadth of the nation. The capability and capacity building that is associated with Digital India is a task by itself. All of these can be achieved through a simple and single programme called Student Remote Sensing \& GIS Programme (SRSGP) as adequate technology / infrastructure/ software tools can be realized in Academic Institutions today.

\section{Proposed Framework for SRSGP as part of INGO/ ISRO- NRSC/ State RSACs/Colleges}

The engineering colleges/Agricultural Institutions with standard computer labs and associated branches can be taken onboard this project to develop local content preferably in local language options, under the guidance of Regional Remote Sensing Centres of ISRO/State Remote Sensing-Space Application Centres/Former Technical employees of ISRO/SOI/NIC and other technical organizations. At a later date, big data can also be applied to add multiple data sets, analysis and evidence based decision making.

Realizing the benefits of GIS, Government of India is visualizing a national GIS (NGIS). As the State GIS is an integral part of such a National GIS, the existing State RSACs and RRSCs can be viewed as the nodal points for Hub \& Spoke model w.r.t Engineering Institutions/Agricultural Institutions in the State/region. NRSC/ISRO provides the data archival data to students and researchers at free of charge or at nominal cost based on the vintage. While this can be used for the training and hands on sessions, the nodal agencies can help to meet the major requirement for availability of required DATA to Students / Academicians in Universities so that R \& D / Applications can be achieved in tune with State GIS / National GIS. Globally, data availability has become relatively more liberal than in the past to enhance services 
It is in this context the National Remote Sensing Policy, liberalizing the data availability is a major boost to SRSGP. Bhuvan, since its inception, has made strides to reach users with wider range of remote sensing data, GIS data services and applications. Bhuvan, the GeoPlatform of ISRO is a gateway to India Earth Observation data and provides easy access to remotely sensed data of medium spatial resolution from Indian satellites [9].

There is need for further liberalization of data availability and free access to general public and especially student community so that students would transform the geospatial data into many application outputs that can be web-enabled and smart-phone enabled. They can also serve as huge constituents of "crowd sourcing" for collection of data on assets, infrastructure, disaster management, crop insurance, etc. using smart phone -based geo-tagging techniques.

Also, the services of retired Remote Sensing, GIS, IT and space professionals can be made use of in the training of students, job seekers in the skill development initiatives. Based on the need and their expertise and interests in addition to the local requirements; can be used either for training or verification and validation of the crowd souring or even training the trainers to reach the required number of professionals in the industry to meet the objectives.

Human resources are needed at all stages of development, implementation and utilization of such RS-GIS services. Hence, training and capacity building is an important component in the success of RS-GIS. It is estimated that nearly 100,000 trained people at various levels of geospatial literacy are needed by 2020 to make India the global destination for RS-GIS applications apart from meeting the domestic requirements for Digital India. This is a huge task and a great opportunity as the global trend is towards Knowledge based societies. Academia participation in human resource development and all premier institutes including agricultural universities need to be equipped with laboratories imparting skills in geospatial data handling in the context of RS-GIS development and implementation.

\subsection{Conclusion}

India's vision of developing smart cities/villages ultimately culminates with the developed smart modern nation. This is where RS and Geospatial Technologies coupled with other ICT solutions can effectively power India's Smart Cities / Villages dream and play a key role in bringing Digital India vision to reality. It requires enormous computational infrastructure and professional HR. An overload situation has started coming for Space Services needed for Digital India. During the last decade, Engineering Institutions have developed good Computer Science/ Information Science computing labs.

Many front-end agricultural Universities and Colleges have also started using RS-GIS in an extensive manner. SRSGP has high potential to spread the RS - GIS across the nation as more computing power becomes available for processing the RS - GIS data. It needs to be viewed in terms of capability and capacity building. ISRO and UGC/AICTE/Academic Institutions can interact /interface and integrate to enhance the spread and services via SRSGP for Digital India.

SRSGP aims at developing RS-GIS applications that can provide hands-on technical training and tangible outcomes to the wider larger student community [10]. The addition of ranking information in the Countries Geospatial Readiness Index (CGRI-2018) and the ways and means to improve the same have been discussed and elaborated.
The classic HUB - Spoke concept as an Institutional Framework can be adopted. The student community has tremendous capability to transform the applications of RS+GIS into societal benefits. The other advantage is that local language content can also be added as local students are available as part of SRSGP which will increase the outreach to all. SRSGP has the potential to make India the global off-shore destination for RS-GIS applications

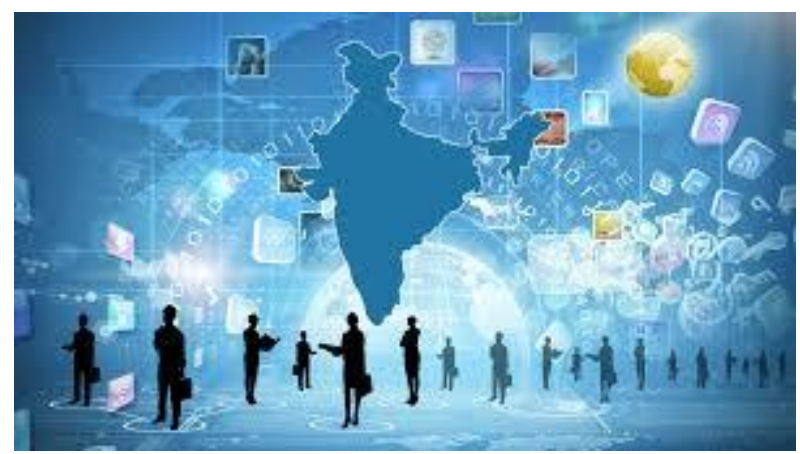

Fig 6. Vision of a True Digital India

\section{Acknowledgements}

The authors are thankful to Sri. P. Kunhikrishnan, Director, URSC. The authors would also like to thank Sri G. Nagesh, Programme Director IRS \& SSS Programme, URSC and many other colleagues at ISRO for the support extended.

\section{References}

1. Sardana, M.M.K. (2012), VISION OF DIGITAL INDIA: Challenges Ahead for Political Establishments 'Information Explosion, Challenges and Opportunities,' DN2012/09, ISID

2. http://www.dnaindia.com/money/report-digital-india-tocontribute-1-trillion-to-the-indian-economy-ravishankarprasad-2195813

3. http://geosmartindia.net/Geoinformatics_Digital.html

4. http://www.r-s-c-c.org

5. http://mhrd.gov.in/university-and-higher-education, MHRD, 2015

6. http://www.tce.edu/ece/laborataries/remote_sensing_lab

7. http://vnit.ac.in/html_vnit/images/remote_sensing_and_gis_lab 1.pdf

8. http://www.isgindia.org/jaipur2015.pdf

9. Bhuvan team, Bhuvan system and software description, NRSCDPPAWA-GWGSG-AUG-15-TR-727, AUG 2015

10. Murthy Remillaa, J.K. Kishore and G.Nagesh., GEOMATICS for Digital India: ISRO-Industry-Academia Collaboration, IACGT, Ahmedabad 2016 